\title{
MicroRNA-138-5p targets the NFIB-Snail1 axis to inhibit colorectal cancer cell migration and chemoresistance
}

\author{
Weifeng $\mathrm{Xu}^{1}$, Beibei Chen ${ }^{1}$, Dianshan $\mathrm{Ke}^{2^{*}}$ and Xiaobing Chen ${ }^{1^{*}}$ (1)
}

\begin{abstract}
Background: Colorectal cancer ranks among the most lethal diseases worldwide. Although much progress has been made in research and treatment of colorectal cancer in recent years, the underlying mechanisms related to migration of the cancer cells and the reason for chemoresistance still remain unclear. In this research, we explored the underlying effect of miR-138-5p in colorectal cancer.

Methods: We used qRT-PCR to investigate the expression of miR-138-5p, Snail1, NFIB in colorectal cancer cells. Lentiviral vectors containing miR-138-5p mimics and inhibitors were constructed and transfected cells. Wound healing assay was applied to illustrate interferences on cell migration. Fluorouracial, doxorubicin, cisplat in were used to detect chemotherapy resistance. In order to identify target genes, bioinformatic methods were applied. Snail1 and NFIB protein expression in stable cell lines was detected using Western blot. Double luciferase and CHIP experiment were used to verify binding sites. We used rescue experiments to further explore the interactions among Snail1, NFIB and miR-138-5p.
\end{abstract}

Results: The expression of miR-138-5p in colorectal cancer cells was low. miR-138-5p inhibited cell migration in colorectal cancer, and could negatively regulate chemotherapy resistance. miR-138-5p targeted NFIB, and regulated Snail1 expression, which mediated colorectal cancer cell migration and chemotherapy resistance.

Conclusions: Our research indicates that miR-138-5p could be a crucial modulator controlling colorectal cancer cell migration and chemoresistance, by acting upon the NFIB-Snail1 axis. miR-138-5p has an emerging prospect to be exploited as a new target for colorectal cancer.

Keywords: Colorectal carcinoma, NFIB-Snail1, Migration, Chemoresistance, miR-138-5p

\section{Background}

Cancer is in the forefront of threatening the public health globally [1]. Colorectal carcinoma ranks the fourth among the most lethal types. Smoking, alcohol, lack of exercise, and overweight are contributing factors to the

\footnotetext{
*Correspondence: xiaobingchen01@163.com; kds8810@163.com ${ }^{1}$ Department of Medical Oncology, The Affiliated Cancer Hospital of Zhengzhou University, 127 Dong Ming Road, Zhengzhou 450008, Henan, People's Republic of China

${ }^{2}$ Department of Cell Biology, Southern Medical University,

510515 Guangzhou, Guangdong, China
}

genesis and poor prognosis of colorectal cancer. Its morbidity and mortality can be mitigated through proper screening and surveillance [2]. Treatments for colorectal cancer include endoscopic and surgical procedures, chemotherapy and radiotherapy [3]. Colonic stenting is also a palliative therapy for unresectable colon cancer [4]. In order to find better treatment options, it is increasingly important to discover novel molecular targets and mechanisms for colorectal cancer.

miRNAs could modulate several important biological processes, such as regulating the expression of cancer initiative and repressive genes. In recent years, miR-138-5p the original author(s) and the source, provide a link to the Creative Commons licence, and indicate if changes were made. The images or other third party material in this article are included in the article's Creative Commons licence, unless indicated otherwise in a credit line to the material. If material is not included in the article's Creative Commons licence and your intended use is not permitted by statutory regulation or exceeds the permitted use, you will need to obtain permission directly from the copyright holder. To view a copy of this licence, visit http://creativecommons.org/licenses/by/4.0/. The Creative Commons Public Domain Dedication waiver (http://creativeco mmons.org/publicdomain/zero/1.0/) applies to the data made available in this article, unless otherwise stated in a credit line to the data. 
was found to reduce cancer growth in several cancers [5-7]. For example, research suggested that in pancreatic cancer, miR-138-5p had a suppressing role [8]. Gao et al's research showed that through targeting EIF4EBP1, it had an impact on nasopharyngeal cancer radiotherapy [9]. Roberto et al. found that the miR-138-5p expression was related to osteosarcoma prognosis [10]. Zhao et al. found that by targeting RHBDD1, it could mitigate progression of breast cancer [11]. Zhu et al's research showed that it intervened in the development of lung cancer [12].

In this study, we explored the underlying mechanisms for the roles of miR-138-5p in colorectal cancer migration and chemoresistance. We found that expression of miR-138-5p was lower in colorectal cancer. We also found that miR-138-5p inhibited colorectal cancer cell migration and chemoresistance. NFIB was discovered as a target gene by using bioinformatics methods. NFIB and Snail 1 were positively correlated. We subsequently performed knock down experiments to define the interactions among miR-138-5p, NFIB and Snail1. Our research provided new insights towards the treatment of colorectal cancer.

\section{Materials and methods}

\section{Patients and samples}

This study was approved by the ethics committee of the Affiliated Cancer Hospital of Zhengzhou University. 100 patients diagnosed with colorectal cancer were selected. All patients had read and signed the informed consent. Cancerous tissues and adjacent corresponding normal tissues were obtained. Samples were immediately frozen and stored in the refrigerator at $-80{ }^{\circ} \mathrm{C}$. Clinical and pathological features of 100 patients were presented in the Table 1.

\section{Bioinformatic methods}

We used miRDB (http://mirdb.org/) [13], DIANA (http:// diana.imis.athena-innovation.gr/) [14], TargetScan (www.targetscan.org) [15] for predicting target genes. GEPIA (http://gepia.cancer-pku.cn/) [16] was utilized to verify correlation between NFIB mRNA and Snail1 mRNA.

\section{Cell culture}

We bought five human colorectal cancer cell lines (LOVO, HCT116, HT29, SW620, SW480) and one normal cell line (FHC) from ATCC (Virginia, USA). All cells were grown in RPMI 1640 (Hy-clone, USA) medium, antibiotics and $100 \mathrm{U} / \mathrm{ml}$ penicillin and $100 \mu \mathrm{g} / \mathrm{ml}$ streptomycin 10\% fetal serum (FBS, Gipco, USA) were added. The cells were cultured in an incubator at a temperature of $37^{\circ} \mathrm{C}$ with $5 \% \mathrm{CO}_{2}$ in a humid atmosphere.
Table 1 Clinical and pathological features of patients

\begin{tabular}{lc}
\hline Features & $\begin{array}{l}\text { Number } \\
\text { of patients }\end{array}$ \\
\hline Age & \\
$\leqq 50$ & 41 \\
$>50$ & 59 \\
Sex & \\
Male & 62 \\
Female & 38 \\
Lymph node status & \\
No & 55 \\
N1 & 39 \\
N2 & 6 \\
Tumor stage & \\
I-II & 79 \\
III-IV & 21 \\
\hline
\end{tabular}

\section{qRT-PCR}

Total RNA was isolated using TRIzol reagent (Invitrogen Life Technologies, USA) and then was reverse-transcribed into cDNA with the Primer Script RT reagent kit (Takara Bio, China). We used SYBR Green PCR Kit (TAKARA, Japan) to perform qRT-PCR. We used U6 and GAPDH as internal controls. The forward primer for miR-138-5p was: 5'-CTAGAGCTCAACTGAAGTGGC TAAACTG $-3^{\prime}$ and reverse primer was $5^{\prime}$-GCTAGGCGT TGAAGTTCTGCCTAAATGC-3'. The forward primer for NFIB was: $5^{\prime}$-GCTGTGTCTTATCCAATCCCG-3' and reverse primer was $5^{\prime}$-TGCCTTTGAACAGGATCA CCA-3 ${ }^{\prime}$. The forward primer for Snail1 was $5^{\prime}$-TCGGAA GCCTAACTACAGCGA-3', and reverse primer was 5'-AGATGAGCATTGGCAGCGAG- ${ }^{\prime}$. The mRNA levels were analyzed using $2^{-\Delta \Delta \mathrm{Ct}}$ method. Three times were replicated for each sample with no RT and no template control.

\section{Western blot}

We used 1\% PMSF and RIPA lysine buffer to confine cellular protein, then reacted with the SDS-PAGE test buffer. Proteins were transferred to a polyvinylide difluoride layer (Millipur, USA). The layer was grown overnight, after incubation for $1 \mathrm{~h}$, at room temperature. Then we applied the ECL chemiluminescence kit (Advansta, USA), and proteins were fried with secondary antibodies for $1 \mathrm{~h}$. We examined bands using GeneGnome 5 (Synoptics Ltd., UK).

\section{Wound healing cell migration assay}

We used Oris Cell Migration Kit (Platypus, USA) to assess cell migration. Cells in the 6-well plates grew 
into full confluence. By scratching the monolayer with a $200-\mu l$ plastic pipette tip, a tiny area was disrupted. We washed the cells twice using phosphate-buffer saline (PBS), then replaced using a complete medium, which contained various concentrations of API. We observed wound closure after $48 \mathrm{~h}$. Under a phase-contrast microscope at $100 \times$ magnification, pictures were captured immediately. Cells were washed with PBS.

\section{CCK-8 assay}

We used cell count-Kit-8 (CCK-8, Dojinto, Japan). We digested the stable strain with $1 \mathrm{ml}$ of $0.25 \%$ trypsin. Then it was transferred to a $15 \mathrm{ml}$ centrifugal tube, later it was centrifuged at $1500 \mathrm{rpm}$ for $5 \mathrm{~min}$. We seeded the cells in six-well plates. After $48 \mathrm{~h}$, we detected cell viability using CCK8. In short, $10 \mu \mathrm{l}$ of $5 \mathrm{mg} / \mathrm{ml}$ CCK 8 solution was added to the 96-well plate. Then it was incubated for $2 \mathrm{~h}$ in the dark. In the microplate, the absorbance of each well was measured at $450 \mathrm{~nm}$.

\section{Generation of lentiviruses and stable transfection} miR-138-5p mimic and its parallel negative control (mNC), miR-138-5b inhibitor and parallel negative control (inhibitor NC) were purchased from RiboBio (Guangzhou, China). Vectors were transfected, plasmids packaged into cells using Polyget Regent (Signage Labs, USA). After $48 \mathrm{~h}$, virus supernatants were collected. In 12-well plates, cancer cells were spin-infected. Then we centrifuged lentiviral supernatants for half an hour. In order to harvest stable cell lines, cells were selected using puromycin $(3 \mathrm{ng} / \mathrm{ml})$. Transient transfections were conducted using Lipofectamine 2000 (Invitrogen, Karlspot, CA, USA).

\section{ChIP-seq analysis and dual-luciferase reporter assay}

We cross-linked cells using the Qiagen PCR Purification kit. We scraped cell monolayers in soft lysis buffer. Then we lysed nuclei pelletsusing SDS lysine buffer. Protein was diluted 1:10 with dilution buffer and precleared by incubating with protein magnetic beads (Millipore). We immunoprecipitated the samples using the initial antibody. Antibody-chromatin complexes were rescued. Then we washed the beads with buffers. The eluted samples were decrosslinked. Next day, we treated the proteins complexes with proteinase $\mathrm{K}$ solution, then incubated them for an hour. We used dual luciferase reporter gene assay kit (Yeasen, China) according to the instruments provided by manufacture.

\section{Statistical analysis}

Data was presented as mean \pm S.D. We used GraphPad Prism 8.0 software and the SPSS25.0 software to conduct all the statistical analyses. Significant difference between each group was analyzed using unpaired 2-tailed Student's $\mathrm{t}$ tests or one-way ANOVA. A $p$ value $<0.05$ was considered statistically significant.

\section{Results}

Expression of miR-138-5p was reduced in colorectal cancer tissues

In 100 colorectal cancer samples, expression of miR$138-5 \mathrm{p}$ was significantly reduced ( $<<0.001)$ (Fig. 1a). Figure $1 \mathrm{~b}$ illustrated that 8 tumor tissues were high and 92 were low in expression. Then, we analyzed expression of miR-138-5p in colorectal cancer samples with and without lymph node metastasis. Results revealed that expression of miR-138-5p in tissues with lymph node metastasis was low, while expression in samples without lymph node metastasis was high $(\mathrm{p}<0.001)$ (Fig. 1c). We further detected miR-138-5p expression in normal colonic cells and 5 colorectal cancer cell lines: FW480, HT29, DLD1, HCT116, LOVO. Results revealed that the expression was decreased in the colorectal cancer cell lines $(\mathrm{p}<0.01)$ (Fig. 1d).

\section{miR-138-5p inhibited cell migration in colorectal cancer}

For further probing the functionality of miR-138-5p in colorectal cancer cells, we knocked down its expressions in DLD1 cells and enhanced its expression in HCT116 cells. Successful knockdown of miR-138-5p could be observed in DLD1 and successful up-regulation in HCT116 cells $(p<0.001)$. We screened out the best mimic and inhibitor sequences (Fig. 2a). To verify the effectiveness of lentivirus transfection, we performed PCR. Compared with control groups, lentiviral vectors containing miR-138-5p inhibitors (LV-inhibitor) group was lower, while the lentiviral vectors containing miR138-5p mimics (LV-mimic) group was higher in expression of miR-138-5p $(\mathrm{p}<0.001)$ (Fig. 2b). Knockdown treated DLD1 cells were examined by scratch test at $0 \mathrm{~h}$ and $48 \mathrm{~h}$. Figure $2 \mathrm{c}$ illustrated that depleted expression of miR-138-5p significantly increased cell migration at $48 \mathrm{~h}$. Cell migration analysis suggested knockdown treatment could increase the DLD1 cell migration $(\mathrm{p}<0.001)$ (Fig. 2d). In HCT116 cell lines, group of LV-mimics was lower in the percentage of cell number compared with LV-mNC group $(\mathrm{p}<0.001)$. In DLD1 cell lines, group of LV-inhibitors increased the percentage of cell number compared with LV-INC group ( $<<0.001)$ (Fig. 2e, f).

\section{miR-138-5p inhibited chemotherapy resistance} of colorectal cancer cells

Three chemotherapy drugs (Fluorouracial, doxorubicin, cisplatin) were used to detect chemotherapy resistance of colorectal cancer cells. For Fluorouracial, in HCT116 cells lines, LV-mimics group was lower in relative cell 

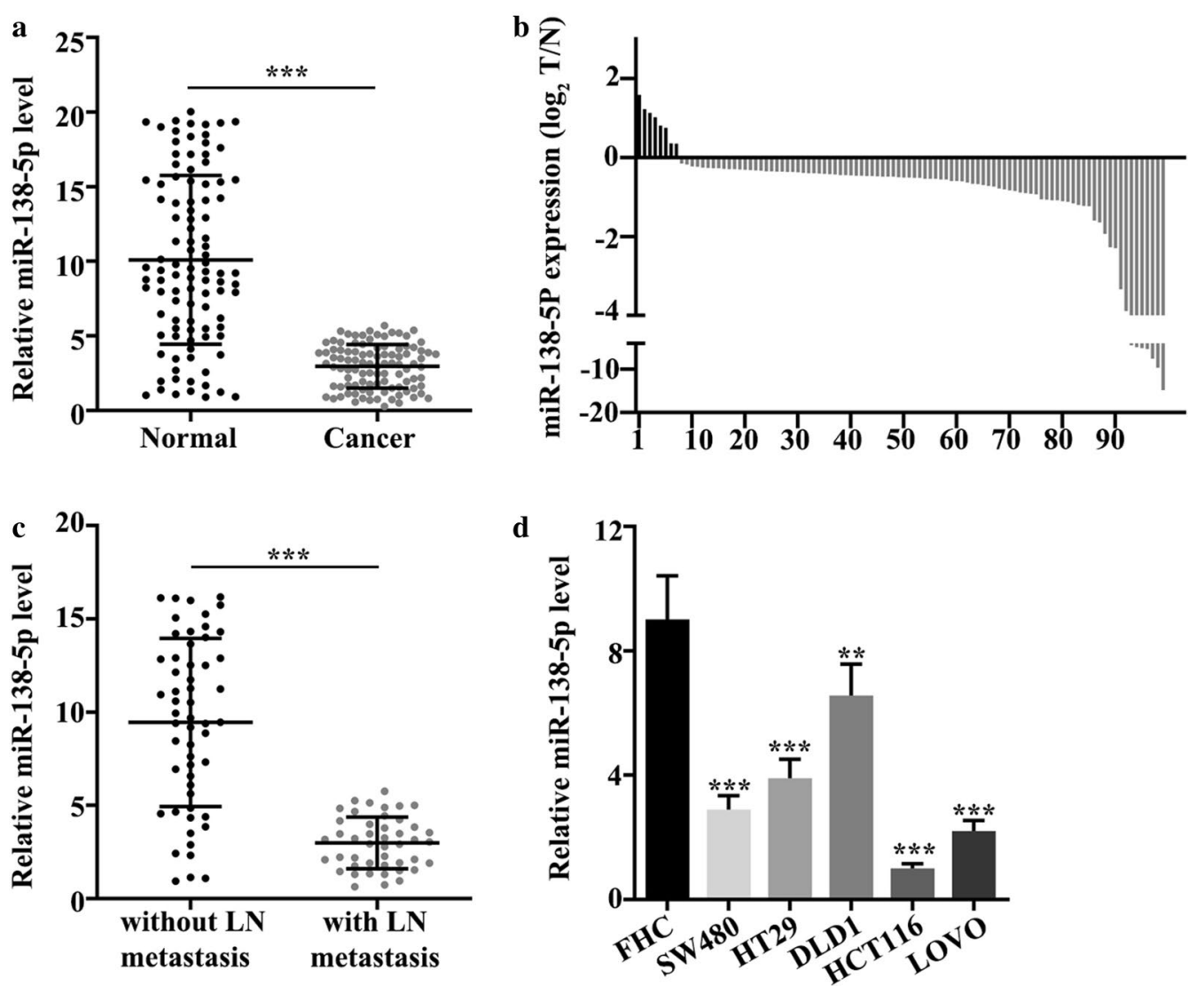

Fig. 1 Expression of miR-138-5p was reduced in colorectal cancer tissues. a miR-138-5p expression was low in colorectal cancer ( $p<0.001)$. b Among 100 samples, 8 were high and 92 were low in expression of miR-138-5p. c Expression in tissues with lymph node metastasis was low, while expression in samples without lymph node metastasis was high $(p<0.001)$. $\mathbf{d}$ Normal colonic mucosal epithelial cells were higher in expression than five colorectal cancer cell lines $(p<0.01)$

viability than $\mathrm{LV}$-mNC group $(\mathrm{p}<0.001)$ (Fig. 3a), in DLD1 cell lines, LV-inhibitor group was higher in relative cell viability than LV-INC group ( $\mathrm{p}<0.001$ ) (Fig. 3b). For Doxorubicin, in HCT116 cells lines, LV-mimics group was lower in relative cell viability than LV-mNC group $(\mathrm{p}<0.001)$ (Fig. 3c), in DLD1 cell lines, LV-inhibitor group was higher in relative cell viability than LV-INC group $(\mathrm{p}<0.001)$ (Fig. 3d). For Cisplatin, in HCT116 cells lines, LV-mimics group was lower in relative cell viability than LV-mNC group ( $<<0.001$ ) (Fig. 3e), in DLD1 cell lines, LV-inhibitor group was higher in relative cell viability than LV-INC group ( $\mathrm{p}<0.001)$ (Fig. 3f).

miR-138-5p modulated Snail 1 expression, which mediated colorectal cancer cell migration and chemotherapy resistance

We detected the relationship between miR-138-5p and Snail1 mRNA and Snail1 protein expression in 100 clinical samples. Figure 4a showed that relative Snail1 mRNA level negatively correlated with level of miR-138-5p $(\mathrm{p}<0.001)$ Fig. 4b showed that relative Snail1 protein level negatively correlated with level of miR-138-5p $(\mathrm{p}<0.001)$. Then we examined Snail1 protein expression in stable cell lines (Fig. 4c). In HCT116 cell lines, LV-mimics group was lower in the expression of Snail1 mRNA than LV-mNC group $(\mathrm{p}<0.001)$. In DLD1 cell lines, LV-inhibitors group was higher in the expression of Snail1 mRNA than LV-INC group (p<0.001) (Fig. 4d). Snail1 siRNA sequences with the best interference effect was screened for subsequent experiments (Fig. 4e, f). In Fluorouracial treated DLD1 cell lines, the difference of relative cell viability between LV-inhibitor + Snail1 siRNA group and LV-INC + Snail1 siRNA group showed no statistical significance ( $>0.05$ ) (Fig. 4g). In Doxorubicin treated DLD1 cell lines, the difference of relative cell viability between LV-inhibitor + Snail1 siRNA group and LV-INC + Snaill siRNA group displayed no significance statistically ( $p>0.05)$ (Fig. 4h) In Cisplatin treated DLD1 cell lines, the difference of relative cell viability between LV-inhibitor + Snail1 siRNA group and LV-INC+Snail1 


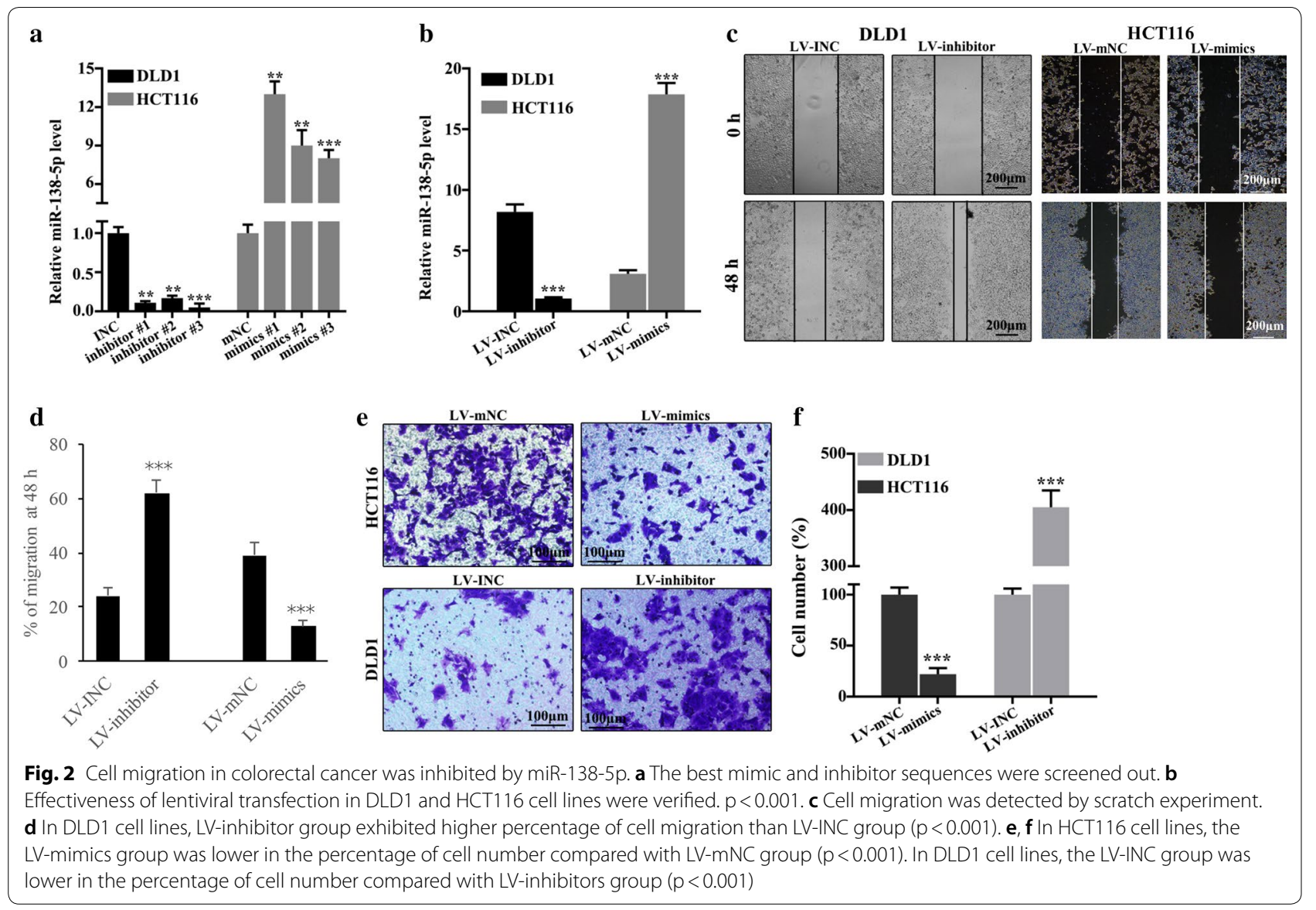

siRNA group was not statistically significant $(p>0.05)$ (Fig. 4i). No significant difference was observed between group LV-inhibitor + Snail1 siRNA and group LVINC + Snail1 siRNA in terms of cell viability (Fig. $4 \mathrm{~g}-\mathrm{i}$ ).

\section{miR-138-5p targeted NFIB}

Target genes were explored using three databases (DIANA, TargetScan, miRDB). NFIB was screened out based on biological function (Fig. 5a). Figure 5b illustrated that relative NFIB mRNA level negatively correlated with relative miR-138-5p level $(\mathrm{p}<0.05)$. Figure $5 \mathrm{c}$ illustrated that relative NFIB protein level negatively correlated with relative miR-138-5p level $(\mathrm{p}<0.05)$ Then we examined NFIB protein expression in stable cell lines (Fig. 5d). In HCT116 cell lines, LV-mimics group was lower in the expression of NFIB protein than LV-mNC group $(\mathrm{p}<0.001)$. In DLD1 cell lines, LV-inhibitors group was higher in the expression of NFIB protein than LVINC group ( $\mathrm{p}<0.001)$ (Fig. 5e). In HCT116 cell lines, LV-mimics group was lower in the expression of NFIB mRNA than LV-mNC group $(\mathrm{p}<0.001)$. In DLD1 cell lines, LV-inhibitors group was higher in the expression of NFIB mRNA than LV-INC group $(\mathrm{p}<0.001)$ (Fig. 5f).
The wild-type and mutant plasmids of NFIB mRNA 3 UTR were constructed on the potential binding sites of miR-138-5p and NFIB mRNA (Fig. 5g). Double luciferase assay verified that miR-138-5p banded with wild type NFIB mRNA 3 UTR instead of mutant type $(\mathrm{p}<0.001)$ (Fig. 5h). The NFIB siRNA with the best interference effect sequences was screened for subsequent experiments (Fig. 5i).

\section{NFIB activated Snail1}

NFIB mRNA and Snaill mRNA expression were in positive correlation in 100 colorectal cancer tissues $(\mathrm{p}<0.001)$ (Fig. 6a). In GEPIA database, NFIB mRNA and Snail1 mRNA expression were positively correlated $(\mathrm{r}=0.646$, $\mathrm{p}<0.001$ ) (Fig. 6b). Expression of Snail1 and NFIB after transfected with NFIB siRNA (Fig. 6c). After transfected with NFIB siRNA, the relative protein level of Snail1 were decreased $(p<0.01)$ (Fig. 6d). After transfected with NFIB siRNA, the relative mRNA level of Snail1 were decreased $(\mathrm{p}<0.01)$ (Fig. 6e). CHIP experiment verified that transcription factor NFIB could bind to the promoter region of Snail1 gene (Fig. 6f). According to the binding sites predicted by the database, wild-type 

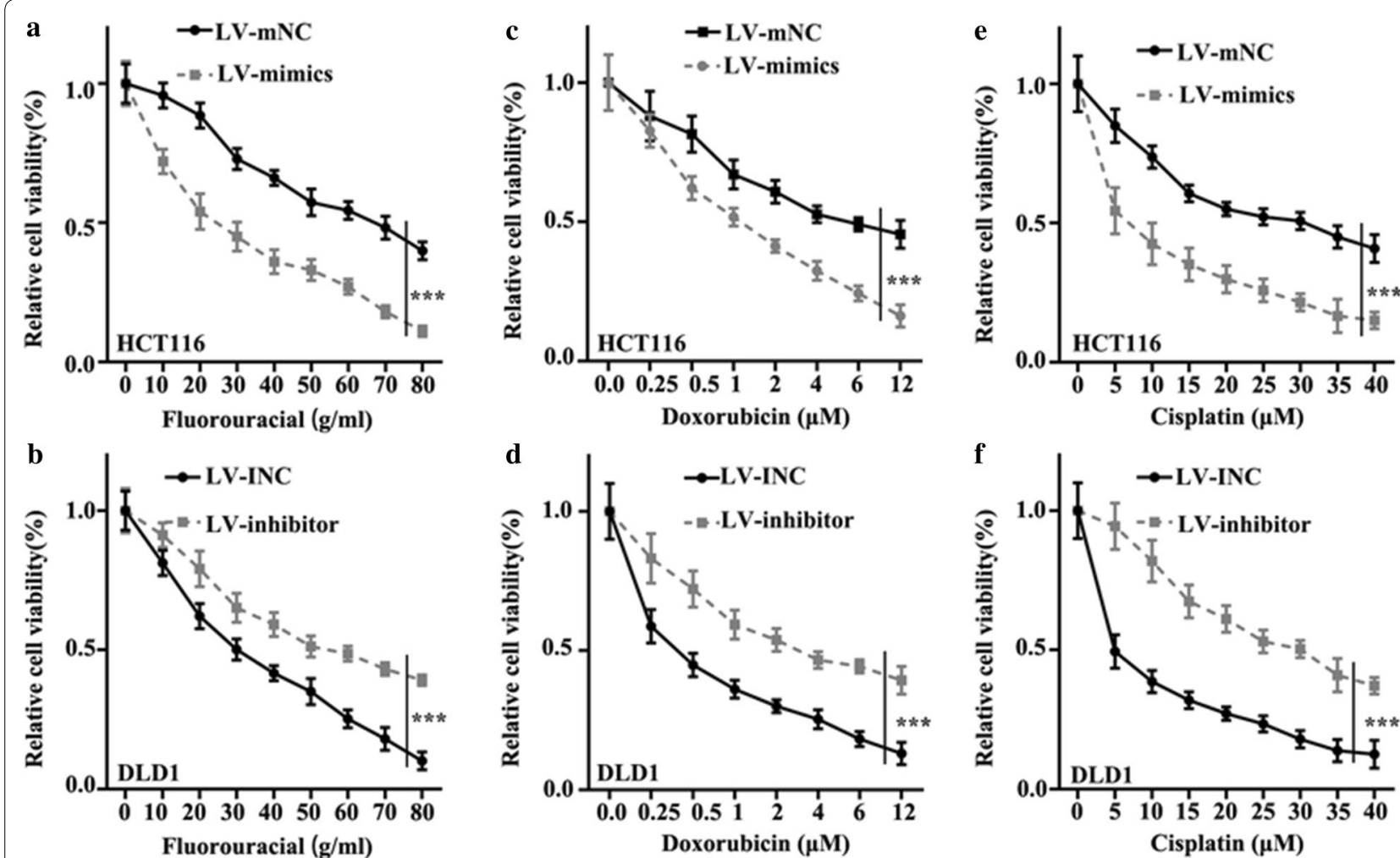

Fig. 3 miR-138-5p could inhibit chemotherapy resistance of colorectal cancer cells. a In Fluorouracial treated HCT116 cell lines, the relative cell viability of LV-mimics group was lower than LV-mNC group $(p<0.001)$. b In Fluorouracial treated DLD1 cell lines, LV-inhibitor group was higher than LV-INC group in cell viability $(p<0.001)$. $\mathbf{c}$ In Doxorubicin treated HCT1 16 cell lines, LV-mimics group was lower than LV-mNC group ( $p<0.001)$. $\mathbf{d}$ In Doxorubicin treated DLD1 cell lines, LV-inhibitor group was higher than LV-INC group $(p<0.001)$. e In Cisplatin treated HCT116 cell lines, LV-mimics group was lower than LV-mNC group $(p<0.001)$. $\mathbf{f}$ In Cisplatin treated DLD1 cell lines, LV-inhibitor group was higher than LV-INC group ( $p<0.001)$

and mutant plasmids of the Snail1 promoter region were constructed. Double luciferase assay experiment verified that NFIB banded to the wild-type promoter region of Snail1, instead of the mutant type (Fig. $6 \mathrm{~g}-\mathrm{i}$ ). Expression of Snail1 was detected after co-transfected NFIB siRNA into stable cell lines. The difference was statistically significant between NFIB siRNA-LV inhibitor + LV INC - group and NFIB siRNA-LV inhibitor-LV INC+ group $(\mathrm{p}<0.001)$ The difference was not statistically significant between NFIB siRNA + LV inhibitor-LV INC+ group and NFIB siRNA + LV inhibitor + LV INCgroup ( $>0.05)$ (Fig. 6j-k).

\section{Discussion}

A large proportion of cancer mortality is attributed to colorectal cancer, and the incidence of colorectal cancer in younger adults has been on the rise $[17,18]$. Although much progress has been made to invent new treatments for combating colorectal cancer, molecular mechanisms of factors that contribute to poor prognosis such as metastasis and drug resistance are still not elucidated. Therefore, finding the key effect or that modulate colorectal cancer metastasis and drug resistance is crucial. It was notable that miR-138-5 manifested important roles in regulating tumorigenesis and progression in several types of cancers [19]. As is highlighted in the literature that miR-138-5p could function as an effective tumor suppressor and monitor cell cycle. Meanwhile, it also participates in other biological processes such as neuronal development [20], autophagy and so on [21].

NFIB is a member of the nuclear factor family (which also includes NFIA, and NFIX). Emerging evidence has demonstrated that NFIB could not only participate in normal somatic development [22], it also acted as an oncogene and involved in tumorigenesis of several cancers, including osteosarcoma [23], glioma [24], astrocytoma [25], gastric cancer [26], breast cancer [27]. Liu et al's research showed that NFIB could suppress p21 transcription [28]. NFIB could also mediate the accessibility of chromatin [29]. The SNAIL1 gene is located in chromosome 20q.13.13. It contains three exons encoding 264 amino acids [30]. Through repressing the adherent and tight junctions, Snaill could effectively promote the epithelial-mesenchymal transition in epithelial 

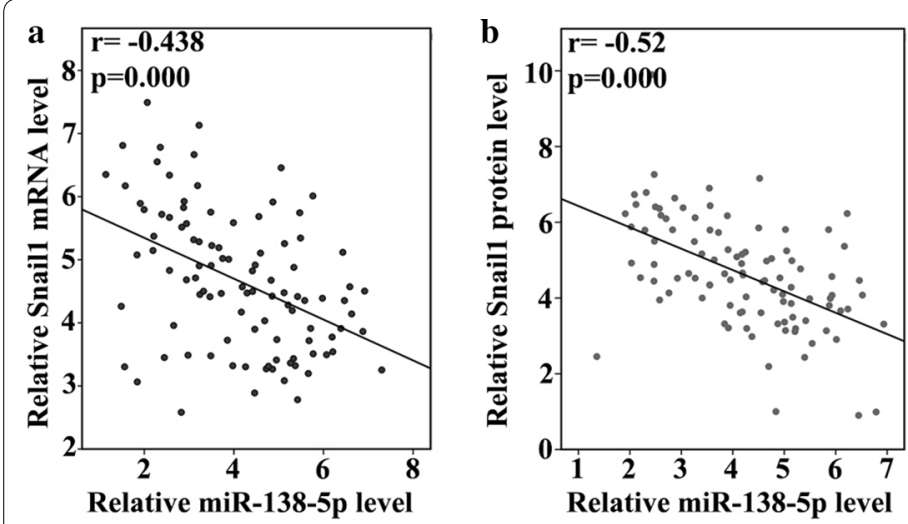

c
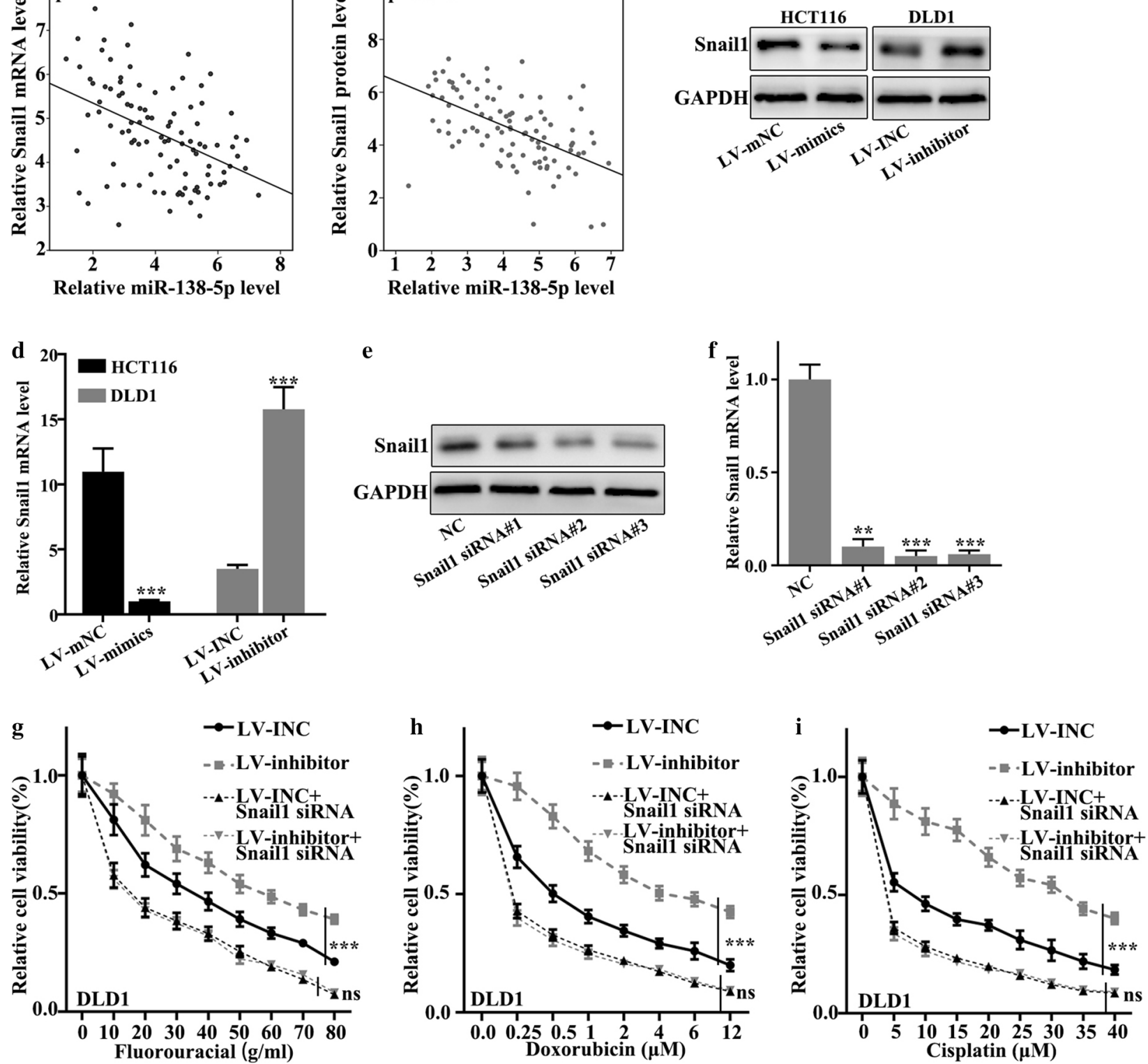

Fig. 4 Snail1 expression mediated colorectal cancer cell migration and chemotherapy resistance and was regulated by miR-138-5p. a Relative Snail 1 mRNA level negatively correlated with relative miR-138-5p level $(r=-0.438, p<0.001)$. b Relative Snail1 protein level negatively correlated with relative miR-138-5p level $(r=-0.52, p<0.001)$. c Snail1 protein expression in stable cell lines. $\mathbf{d}$ In HCT116 cell lines, LV-mimics group was lower in the expression of Snail1 mRNA than LV-mNC group $(p<0.001)$. In DLD1 cell lines, LV-inhibitors group was higher in the expression of Snail1 mRNA than LV-INC group $(p<0.001)$. e, $\mathbf{f}$ Snail 1 siRNA sequences with the best interference effect was screened for subsequent experiments. $\mathbf{g}$ In Fluorouracial treated DLD1 cell lines, the difference of relative cell viability between LV-inhibitor + Snail1 siRNA group and LV-INC + Snail1 siRNA group showed no statistical significance $(p>0.05)$. $\mathbf{h}$ In Doxorubicin treated DLD1 cell lines, the difference of relative cell viability between LV-inhibitor + Snail1 siRNA group and LV-INC + Snail1 siRNA group was not statistically significant $(p>0.05)$. i In Cisplatin treated DLD1 cell lines, the difference of relative cell viability between LV-inhibitor + Snail1 siRNA group and LV-INC + Snail1 siRNA group was not statistically significant $(p>0.05)$

cells, leading to cell migratory and tumor progression [31]. Emerging evidence has suggested that Snail1 acted as an important regulator of epithelial-mesenchymal transition. Snail1 could inhibit molecules such as E-cadherin and claudins (cell adhesion related), and promote cell migratory capacity. Cell adhesion, polarity and 

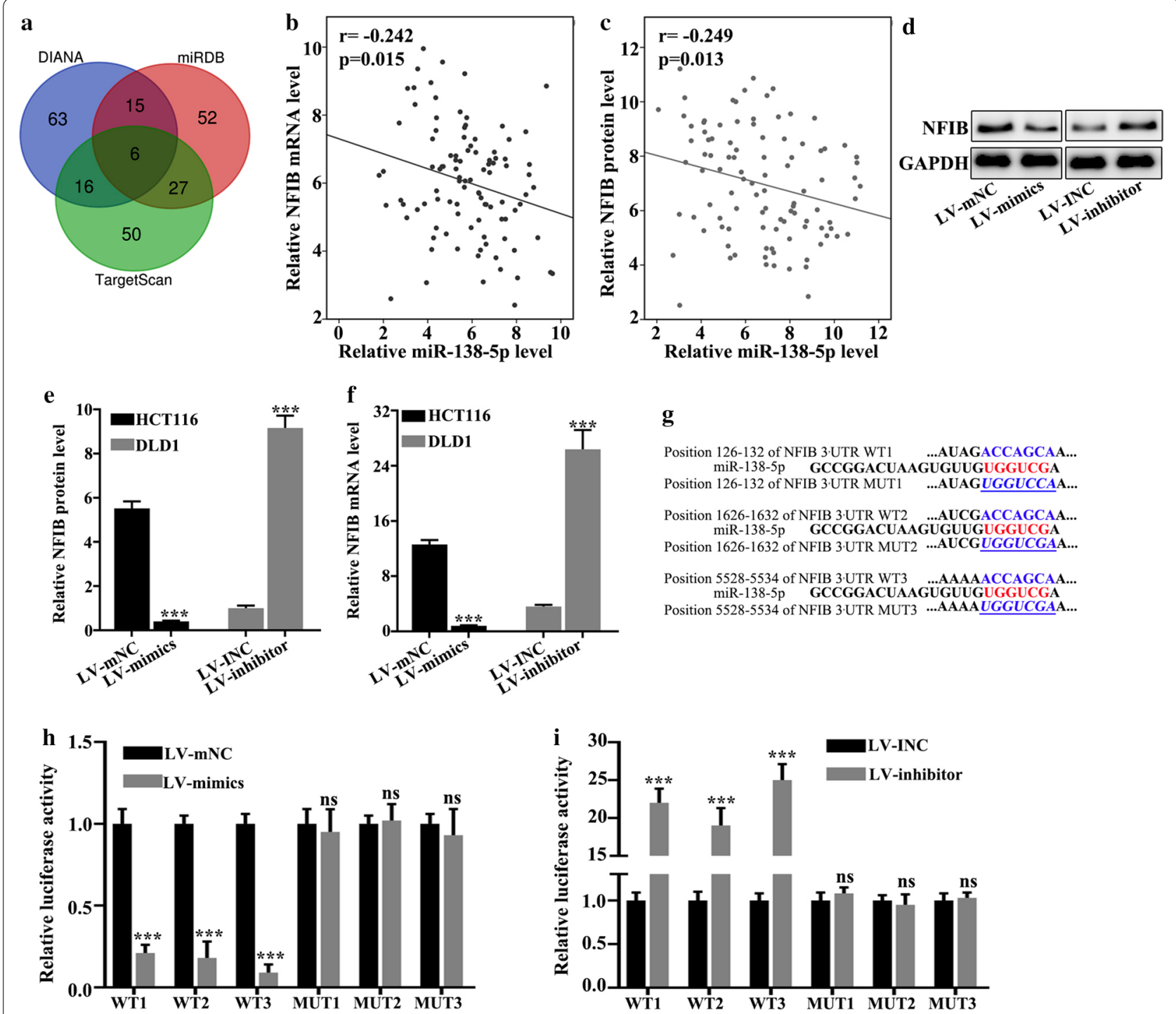

Fig. 5 miR-138-5p targeted NFIB. a Target genes of miR-138-5 $p$ were predicted by three databases, and NFIB was screened out based on biological function. b Relative NFIB mRNA level negatively correlated with relative miR-138-5p level $(r=-0.242, p<0.05)$. c Relative NFIB protein level negatively correlated with relative miR-138-5p level $(r=-0.249, p<0.05)$. d NFIB protein expression in stable cell lines. e In HCT116 cell lines, LV-mimics group was lower in the expression of NFIB protein than LV-mNC group $(p<0.001)$. In DLD1 cell lines, LV-inhibitors group was higher in the expression of NFIB protein than LV-INC group $(p<0.001)$. $\mathbf{f}$ In HCT116 cell lines, LV-mimics group was lower in the expression of NFIB mRNA than LV-mNC group $(p<0.001)$. In DLD1 cell lines, LV-inhibitors group was higher in the expression of NFIB mRNA than LV-INC group ( $p<0.001)$. $\mathbf{g}$ The wild-type and mutant plasmids of NFIB mRNA 3 UTR were constructed on the potential binding sites of miR-138-5p and NFIB mRNA. $\mathbf{h}$ Double luciferase assay verified that miR-138-5p banded with wild type NFIB mRNA 3 UTR instead of mutant type $(p<0.001)$. i The NFIB siRNA with the best interference effect sequences was screened for subsequent experiments

migratory properties change during epithelial-mesenchymal transition. SNAIL1 also participates in several crucial signaling pathways, such as RTKs, TGF $\beta$, NOTCH, WNT, TNF $\alpha$ and BMPs pathways [32]. Study by Frey et al. demonstrated that Snail1 employed canonical BMP signaling in colorectal cancer [33]. Literature demonstrates that Snail1 is a key effector in modulating biological process in breast cancer [34, 35], pancreatic cancer [36], lung cancer [37], glioma [38], gastric cancer [39], multiple myeloma [40] and melanoma [41]. Research also revealed that Snail1 could regulate neoangiogenesis [42].

In our research, expression level of miR-138-5p in 100 colorectal cancer tissues and cancer cell lines were examined, and in colorectal cancer, expression was decreased. Colorectal cancer tissues with and without lymph node 


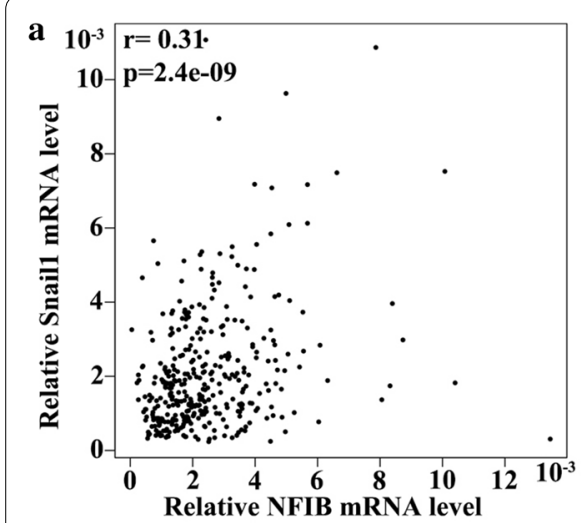

c

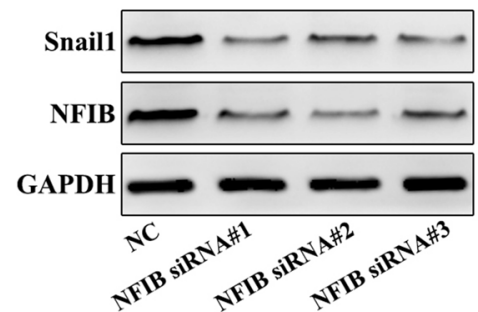

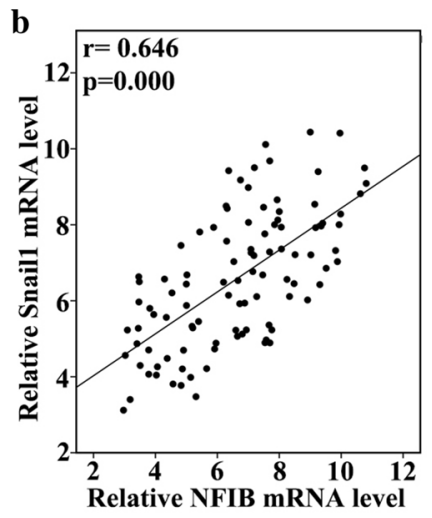

\section{(1)}

f

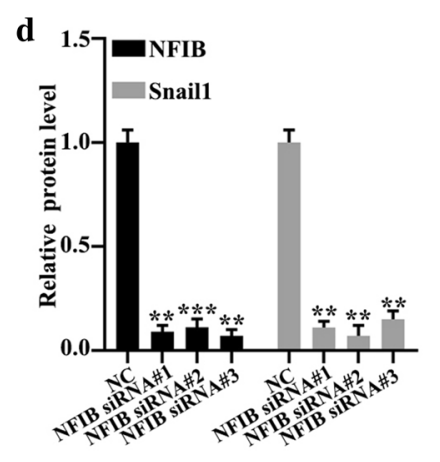

g
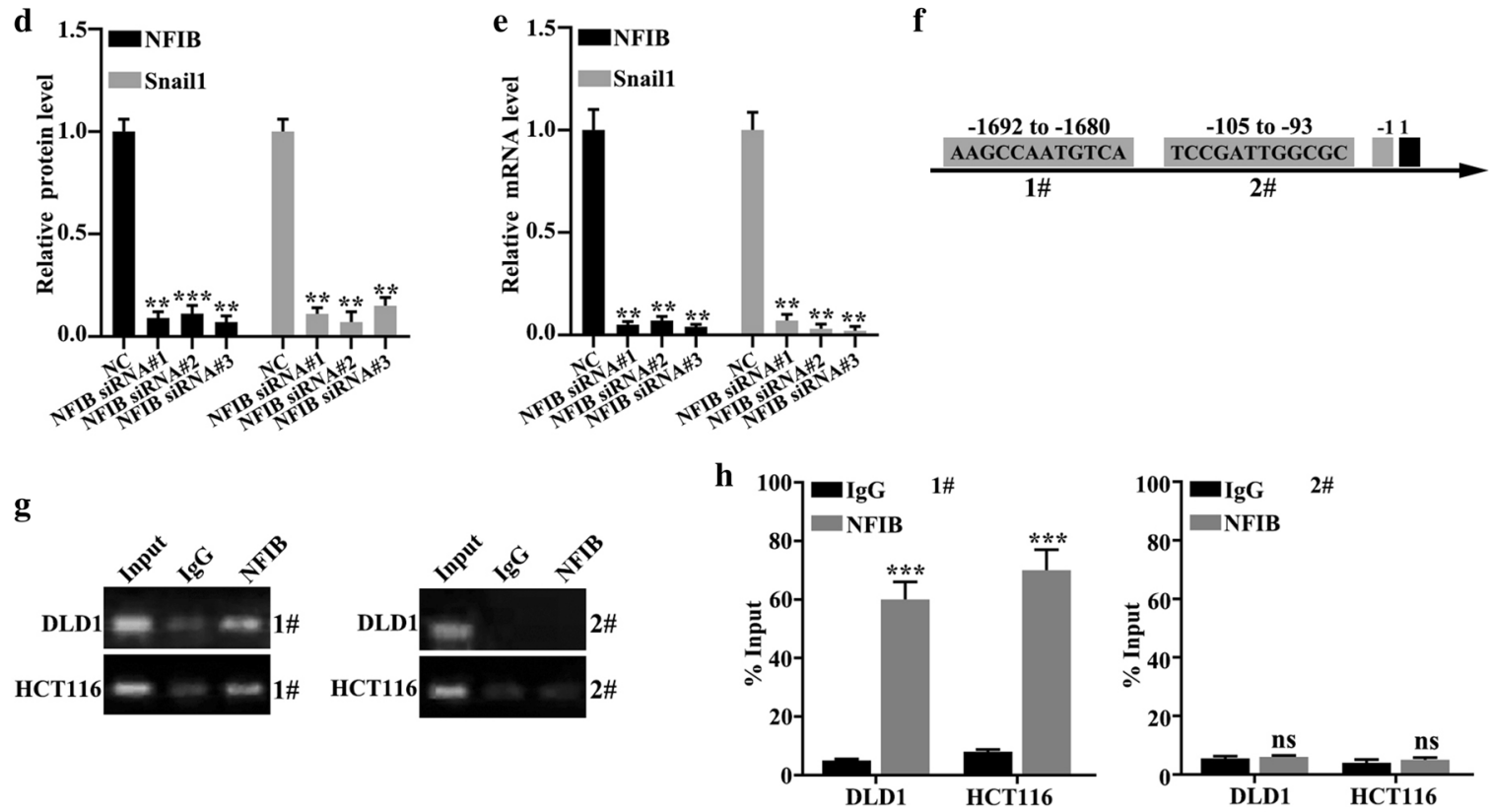

i
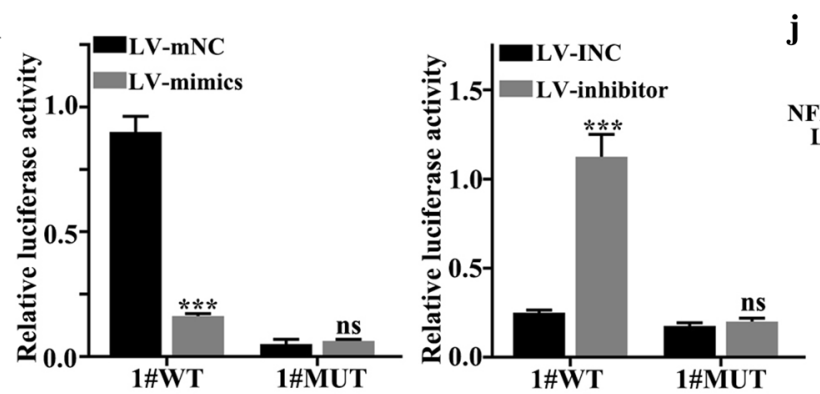

j

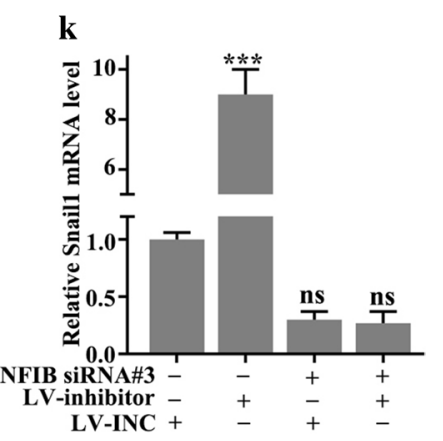

Fig. 6 NFIB activated Snail1. a NFIB mRNA and Snail1 mRNA expression had positive correlation in 100 colorectal cancer tissues $(r=0.31, p<0.001)$. b In GEPIA database, NFIB mRNA and Snail1 mRNA expression were positively correlated $(r=0.646, p<0.001)$. c Expression of Snail 1 and NFIB after transfected with NFIB siRNA. d After transfected with NFIB siRNA, the relative protein level of Snail1 were decreased $(p<0.01)$. e After transfected with NFIB siRNA, the relative mRNA level of Snail1 were decreased $(p<0.01)$. $\mathbf{f} C$ HIP experiment verified that transcription factor NFIB could bind to the promoter region of Snail1 gene. $\mathbf{g}-\mathbf{i}$. According to the binding sites predicted by the database, wild-type and mutant plasmids of the Snail1 promoter region were constructed. Double luciferase assay experiment verified that NFIB binded to the wild-type promoter region of Snail1, instead of the mutant type. $\mathbf{j}-\mathbf{k}$ Expression of Snail 1 was detected after co-transfected NFIB siRNA into stable cell lines. The difference was statistically significant between NFIB siRNA-LV inhibitor + LV INC - group and NFIB siRNA-LV inhibitor-LV INC + group $(p<0.001)$ The difference was not statistically significant between NFIB siRNA + LV inhibitor-LV INC + group and NFIB siRNA + LV inhibitor + LV INC - group $(p>0.05)$ 
metastasis were studied further. Results revealed that samples without lymph node metastasis were higher in expression, which was statistically significant. Results implied that miR-138-5p participated in the down regulation of the metastasis process of colorectal cancer. Scratch test showed that by administration of miR455-3p inhibitor, colorectal cancer cell migration was promoted, which elucidated that miR-455-3p suppressed migration of colorectal cancer cell. Fluorouracial, doxorubicin, and cisplatin were used to detect chemotherapy resistance of colorectal cancer and results indicated that chemotherapy resistance could be inhibited by miR138-5p. In addition, the difference of cell viability of LVinhibitor + Snail1 siRNA and LV-INC+Snaill siRNA groups was not statistically difference. NFIB was discovered as target gene of miR-138-5p using bioinformatics methods. NFIB and Snail1 were negatively correlated with miR-138-5p, while NFIB and Snail1 were positively correlated. We performed the rescue experiments to demonstrate the interactions among miR-138-5p, NFIB and Snail1. Altogether, our study unvailed that miR138-5p targeted the NFIB-Snail1 axis to inhibit migration and chemoresistance of colorectal cancer cells.

In the present study, FHC was used as normal cell line. However, previous study indicated that FHC exhibited tumorigenic phenotype, complex karyotype, and TP53 gene mutation [43]. Therefore, other normal colon cell lines need to be applied to validate the conclusion of this study.

\section{Conclusions}

In conclusion, we found that colorectal cancer cells were low in expression of miR-138-5p. Through targeting NFIB-Snail1 axis miR-138-5p could regulate colorectal cancer cell migration andchemoresistance. Our research shed new light in understanding colorectal cancer migration and chemoresistance. Further research is needed for miR-138-5p to be exploited for novel treatment of colorectal cancer.

\footnotetext{
Abbreviations

PBS: Phosphate-buffer saline; NC: Negative control; LV-inhibitor: Lentiviral vectors containing miR-138-5p inhibitors; LV-mimic: Lentiviral vectors containing miR-138-5p mimics.
}

\section{Acknowledgements \\ None.}

\section{Authors' contributions}

WX and $X C$ conceived and designed the project; $B C$ and DK collected the data; $W X$ performed the interpretation of data and statistical analysis; $W X$ wrote the manuscript; $X C$ revised the paper. All authors read and approved the final manuscript.

\section{Funding}

None.
Availability of data and materials

All data generated or analysed during this study are included in this published article.

\section{Ethics approval and consent to participate}

This study was approved by the ethics committee of the Affiliated Cancer Hospital of Zhengzhou University. All patients had read and signed the informed consent.

\section{Consent for publication \\ Not applicable.}

\section{Competing interests}

The authors declare that they have no competing interests.

Received: 5 August 2020 Revised: 19 September 2020 Accepted: 23 September 2020

Published online: 01 October 2020

\section{References}

1. Siegel RL, Miller KD, Jemal A. Cancer statistics, 2020. CA Cancer J Clin. 2020;70(1):7-30.

2. Siegel RL, Miller KD, Goding Sauer A, Fedewa SA, Butterly LF, Anderson JC, Cercek A, Smith RA, Jemal A. Colorectal cancer statistics, 2020. CA Cancer J Clin. 2020;70(3):145-64.

3. Brown KGM, Solomon MJ, Mahon K, O'Shannassy S. Management of colorectal cancer. BMJ. 2019;366:14561.

4. Keller DS, Berho M, Perez RO, Wexner SD, Chand M. The multidisciplinary management of rectal cancer. Nat Rev Gastroenterol Hepatol. 2020;17(7):414-29.

5. Yang J, Yang XS, Zhang Q, Zhuang X, Dong XK, Jiang YH, Tao YN, Yang CH. Downregulated LINC01614 ameliorates hypoxia/reoxygenation-stimulated myocardial injury by directly sponging microRNA-138-5p. Dose Response. 2020;18(1):1559325820913786.

6. Deng Y, Chen D, Gao F, Lv H, Zhang G, Sun X, Liu L, Mo D, Ma N, Song L, et al. Exosomes derived from microRNA-138-5p-overexpressing bone marrow-derived mesenchymal stem cells confer neuroprotection to astrocytes following ischemic stroke via inhibition of LCN2. J Biol Eng. 2019;13:71.

7. Yu C, Wang M, Li Z, Xiao J, Peng F, Guo X, Deng Y, Jiang J, Sun C. MicroRNA-138-5p regulates pancreatic cancer cell growth through targeting FOXC1. Cell Oncol. 2015:38(3):173-81.

8. Yu C, Wang M, Chen M, Huang Y, Jiang J. Upregulation of microRNA1385p inhibits pancreatic cancer cell migration and increases chemotherapy sensitivity. Mol Med Rep. 2015;12(4):5135-40.

9. Gao W, Lam JW, Li JZ, Chen SQ, Tsang RK, Chan JY, Wong TS. MicroRNA138-5p controls sensitivity of nasopharyngeal carcinoma to radiation by targeting EIF4EBP1. Oncol Rep. 2017;37(2):913-20.

10. Roberto GM, Lira RC, Delsin LE, Vieira GM, Silva MO, Hakime RG, Yamashita $M E$, Engel EE, Scrideli CA, Tone LG, et al. microRNA-138-5p as a worse prognosis biomarker in pediatric, adolescent, and young adult osteosarcoma. Pathol Oncol Res. 2020;26(2):877-83.

11. Zhao C, Ling X, Li X, Hou X, Zhao D. MicroRNA-138-5p inhibits cell migration, invasion and EMT in breast cancer by directly targeting RHBDD1. Breast Cancer. 2019;26(6):817-25.

12. Zhu D, Gu L, Li Z, Jin W, Lu Q, Ren T. MiR-138-5p suppresses lung adenocarcinoma cell epithelial-mesenchymal transition, proliferation and metastasis by targeting ZEB2. Pathol Res Pract. 2019;215(5):861-72.

13. Chen $Y$, Wang $X$. miRDB: an online database for prediction of functional microRNA targets. Nucleic Acids Res. 2020;48(D1):D127-31.

14. Vlachos IS, Vergoulis T, Paraskevopoulou MD, Lykokanellos F, Georgakilas G, Georgiou P, Chatzopoulos S, Karagkouni D, Christodoulou F, Dalamagas T, et al. DIANA-mirExTra v2.0: uncovering microRNAs and transcription factors with crucial roles in NGS expression data. Nucleic Acids Res. 2016;44(W1):W128-34.

15. Mon-Lopez D, Tejero-Gonzalez CM. Validity and reliability of the TargetScan ISSF Pistol \& Rifle application for measuring shooting performance. Scand J Med Sci Sports. 2019;29(11):1707-12. 
16. Tang Z, Li C, Kang B, Gao G, Li C, Zhang Z. GEPIA: a web server for cancer and normal gene expression profiling and interactive analyses. Nucleic Acids Res. 2017;45(W1):W98-102.

17. Bromham N, Kallioinen M, Hoskin P, Davies RJ, Guideline C. Colorectal cancer: summary of NICE guidance. BMJ. 2020;368:m461.

18. Dekker E, Tanis PJ, Vleugels JLA, Kasi PM, Wallace MB. Colorectal cancer. Lancet. 2019;394(10207):1467-80.

19. Wang J, Li J, Yang J, Zhang L, Gao S, Jiao F, Yi M, Xu J. MicroRNA1385p regulates neural stem cell proliferation and differentiation in vitro by targeting TRIP6 expression. Mol Med Rep. 2017;16(5):7261-6.

20. Weiss K, Treiber T, Meister G, Schratt G. The nuclear matrix protein Matr3 regulates processing of the synaptic microRNA-138-5p. Neurobiol Learn Mem. 2019:159:36-45.

21. Ma J, Zhang Y, Ji H, Chen L, Chen T, Guo C, Zhang S, Jia J, Niu P. Overexpression of miR-138-5p suppresses $\mathrm{MnCl} 2$-induced autophagy by targeting SIRT1 in SH-SY5Y cells. Environ Toxicol. 2019;34(4):539-47.

22. Becker-Santos DD, Lonergan KM, Gronostajski RM, Lam WL. Nuclear Factor I/B: a master regulator of cell differentiation with paradoxical roles in cancer. EBioMedicine. 2017;22:2-9.

23. Sun F, Yu Z, Wu B, Zhang H, Ruan J. LINC00319 promotes osteosarcoma progression by regulating the miR-455-3p/NFIB axis. J Gene Med. 2020. https://doi.org/10.1002/jgm.3248.

24. Li Y, Xu J, Zhang J, Zhang J, Zhang J, Lu X. MicroRNA-346 inhibits the growth of glioma by directly targeting NFIB. Cancer Cell Int. 2019;19:294.

25. Chen KS, Bridges CR, Lynton Z, Lim JWC, Stringer BW, Rajagopal R, Wong KT, Ganesan D, Ariffin H, Day BW, et al. Transcription factors NFIA and NFIB induce cellular differentiation in high-grade astrocytoma. J Neurooncol. 2020;146(1):41-53.

26. Wu C, Zhu X, Liu W, Ruan T, Wan W, Tao K. NFIB promotes cell growth, aggressiveness, metastasis and EMT of gastric cancer through the Akt/ Stat3 signaling pathway. Oncol Rep. 2018;40(3):1565-73.

27. Moon HG, Hwang KT, Kim JA, Kim HS, Lee MJ, Jung EM, Ko E, Han W, Noh DY. NFIB is a potential target for estrogen receptor-negative breast cancers. Mol Oncol. 2011;5(6):538-44.

28. Liu RZ, Vo TM, Jain S, Choi WS, Garcia E, Monckton EA, Mackey JR, Godbout R. NFIB promotes cell survival by directly suppressing p21 transcription in TP53-mutated triple-negative breast cancer. J Pathol. 2019;247(2):186-98

29. Liu Z, Chen J, Yuan W, Ruan H, Shu Y, Ji J, Wu L, Tang Q, Zhou Z, Zhang $X$, et al. Nuclear factor I/B promotes colorectal cancer cell proliferation, epithelial-mesenchymal transition and 5-fluorouracil resistance. Cancer Sci. 2019;110(1):86-98.

30. Wang Y, Yan T, Li J, Wang W, Wu Q, Shi J, Li D, Stovall DB, Zhang Q, Sui G. The SNAIL1 promoter contains G-quadruplex structures regulating its gene expression and DNA replication. Exp Cell Res. 2020;2020:112158.

31. Baulida J, Diaz VM, Herreros AG. Snail1: a transcriptional factor controlled at multiple levels. J Clin Med. 2019;8(6):757.
32. Herrera A, Herrera M, Pena C. The emerging role of Snail1 in the tumor stroma. Clin Transl Oncol. 2016;18(9):872-7.

33. Frey P, Devisme A, Schrempp M, Andrieux G, Boerries M, Hecht A. Canonical BMP signaling executes epithelial-mesenchymal transition downstream of SNAIL1. Cancers. 2020:12(4):1019.

34. Maturi V, Moren A, Enroth S, Heldin CH, Moustakas A. Genomewide binding of transcription factor Snail1 in triple-negative breast cancer cells. Mol Oncol. 2018;12(7):1153-74.

35. Brenot A, Knolhoff BL, DeNardo DG, Longmore GD. SNAIL1 action in tumor cells influences macrophage polarization and metastasis in breast cancer through altered GM-CSF secretion. Oncogenesis. 2018;7(3):32.

36. Fendrich $V$, Jendryschek F, Beeck S, Albers M, Lauth M, Esni F, Heeger K, Dengler J, Slater EP, Holler JPN, et al. Genetic and pharmacologic abrogation of Snail1 inhibits acinar-to-ductal metaplasia in precursor lesions of pancreatic ductal adenocarcinoma and pancreatic injury. Oncogene. 2018;37(14):1845-56.

37. Zhang J, Hua X, Qi N, Han G, Yu J, Yu Y, Wei X, Li H, Chen X, Leng C, et al. MiR-27b suppresses epithelial-mesenchymal transition and chemoresistance in lung cancer by targeting Snail 1. Life Sci. 2020;254:117238.

38. Li J, Qu J, Shi Y, Perfetto M, Ping Z, Christian L, Niu H, Mei S, Zhang Q, Yang $X$, et al. Nicotinic acid inhibits glioma invasion by facilitating Snail1 degradation. Sci Rep. 2017;7:43173.

39. Yu S, Zhang Y, Li Q, Zhang Z, Zhao G, Xu J. CLDN6 promotes tumor progression through the YAP1-snail 1 axis in gastric cancer. Cell Death Dis. 2019;10(12):949.

40. Huang Z, Liang X, Wu W, Chen X, Zeng Q, Yang M, Ge J, Xia R. Mechanisms underlying the increased chemosensitivity of bortezomib-resistant multiple myeloma by silencing nuclear transcription factor Snail1. Oncol Rep. 2019;41(1):415-26.

41. Maiques O, Barcelo C, Panosa A, Pijuan J, Orgaz JL, Rodriguez-Hernandez I, Matas-Nadal C, Tell G, Vilella R, Fabra A, et al. T-type calcium channels drive migration/invasion in BRAFV600E melanoma cells through Snail1. Pigment Cell Melanoma Res. 2018;31(4):484-95.

42. Zhang YK, Wang H, Guo YW, Yue Y. Novel role of Snail 1 in promoting tumor neoangiogenesis. Biosci Rep. 2019. https://doi.org/10.1042/BSR20 182161.

43. Soucek K, Gajduskova P, Brazdova M, Hyzd'alova M, Koci L, Vydra D, Trojanec R, Pernicova Z, Lentvorska L, Hajduch M, et al. Fetal colon cell line FHC exhibits tumorigenic phenotype, complex karyotype, and TP53 gene mutation. Cancer Genet Cytogenet. 2010;197(2):107-16.

\section{Publisher's Note}

Springer Nature remains neutral with regard to jurisdictional claims in published maps and institutional affiliations.
Ready to submit your research? Choose BMC and benefit from:

- fast, convenient online submission

- thorough peer review by experienced researchers in your field

- rapid publication on acceptance

- support for research data, including large and complex data types

- gold Open Access which fosters wider collaboration and increased citations

- maximum visibility for your research: over $100 \mathrm{M}$ website views per year

At $\mathrm{BMC}$, research is always in progress.

Learn more biomedcentral.com/submissions 